\title{
Recent progress in microRNA-based delivery systems for the treatment of human disease
}

\author{
Yong $\mathrm{Fu}^{1}$, Jiangning Chen ${ }^{1,2}$ and Zhen Huang ${ }^{1 *}$ (D)
}

\begin{abstract}
MicroRNAs (miRNAs) are naturally occurring, small non-coding RNAs that mediate posttranscriptional regulation. Based on the level of sequence complementarity, miRNAs lead to the degradation of target mRNAs or the suppression of mRNA translation, thereby inhibiting the synthesis of proteins and achieving the regulation of genes. miRNAs, which exhibit tissue- and temporal- specific expression, are important negative regulatory RNAs that decrease the levels of other functional genes. miRNAs play a crucial role in disease progression and prognosis and thus exhibit potential for developing novel therapeutics. Due to the instability of miRNAs and their complex environment, including degradation by nucleases in vivo, the safety and effectiveness of miRNA delivery has become the focus of recent attention.

Therefore, we discuss some representative advances related to the application of viral- and nonviral-mediated miRNA delivery systems and provide a new perspective on the future of miRNA-based therapeutic strategies.
\end{abstract}

Keywords: microRNA, microRNA delivery, Viral vectors, Nonviral vectors

\section{Background}

MicroRNAs (miRNAs) comprise a group of small non-coding RNAs 18 25 nucleotides (nt) in length that posttranscriptionally regulate gene expression via binding to the 3 '-untranslated regions (3'-UTRs) of target gene mRNA [1, 2]. Most miRNAs have highly conserved sequences and are tissue- and temporal-specific [3]. Reports have demonstrated that miRNAs participate in different physiological responses, including development, organogenesis, viral defense, hematopoietic processes, cell proliferation/apoptosis and fat metabolism [4-8]. In 1993, the first miRNA known as lin-4 was discovered in the nematode Caenorhabditis elegans via genetic screening [9]. This small RNA can suppress the expression level of nuclear protein LIN-14 and thus regulates the development of nematodes [10]. Since that study, large numbers of miRNAs have been discovered in humans, mice, zebrafish, fruit flies, Arabidopsis thaliana, rice and other animals and plants.

\footnotetext{
* Correspondence: zhenhuang@nju.edu.cn

'State Key Laboratory of Pharmaceutical Biotechnology, School of Life

Sciences, Nanjing University, Nanjing 210093, Jiangsu, China

Full list of author information is available at the end of the article
}

Briefly, RNA polymerase II transcribes miRNA genes, leading to the formation of long precursor transcripts named primary miRNAs (pri-miRNAs), which have stem-loop structures consisting of hundreds of nucleotides. In the nucleus, each pri-miRNA is processed by ribonuclease Drosha into a 70- to 100-nt hairpin structure, denoted a premiRNA. Then, the premiRNA is transported into the cytoplasm by a shuttle system composed of Exportin 5 and Ran. There, each premiRNA is further cleaved into a double-stranded miRNA duplex containing $22 \mathrm{nt}$ by Dicer and each mature miRNA strand binds to the miRNA-induced silencing complex (miRISC); however, the antisense miRNA strand (also known as miRNA*) is subsequently degraded. The miRISC complex containing a mature miRNA strand can bind to the 3'-UTR of target gene mRNA. This specific binding between miRNA and target mRNA leads to the repression of protein synthesis and the subsequent degradation of the targeted mRNA [11] (Fig. 1).

Usually, miRISC recognizes mRNA through complementary base pairing of the miRNA with the target gene mRNA. Under some circumstances, the binding between miRISC and target gene mRNAs does not require perfect pairing [12]. Moreover, reports have indicated that 


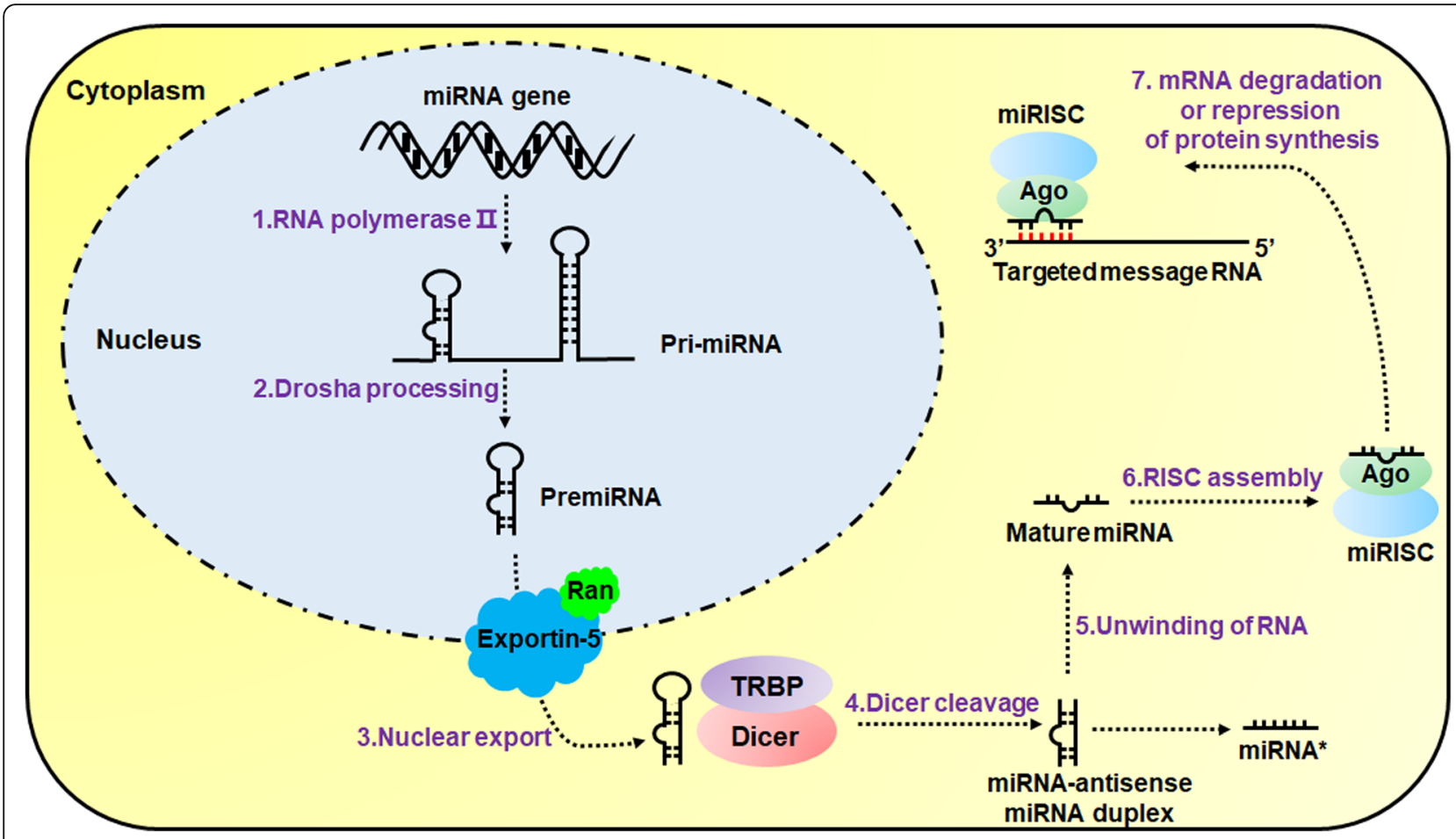

Fig. 1 Schematic illustration of the biogenesis and function of miRNA

miRNA can also bind to the $5^{\prime}$-UTR of target genes [13]. The binding of miRISC to an mRNA can lead to either the repression or promotion of translation, although the latter is quite rare [14].

\section{Tissue and temporal specificity}

The expression of most miRNAs occurs in a tissue- and temporal- specific manner [3]. Recently, miRNA expression profiling studies of multiple tumor types have revealed that aberrantly expressed miRNAs are beneficial for the classification, diagnosis, staging, and prognosis of disease [15]. The analysis of sequencing data from 27 different organs/tissues of Arabidopsis also proved that most miRNAs are widely expressed, whereas a fraction of miRNAs exhibit tissue-specific expression patterns [16].

\section{Circulating miRNA}

Recent research has reported that a large number of stable miRNAs derived from various organs/tissue exist in body fluids, and these miRNAs are promising as novel biomarkers for the diagnosis of cancer and other immune-related diseases via expression profiling. miRNA-21 was the first miRNA discovered in serum [17]. In addition to working inside cells, miRNAs also communicate remotely in the form of circulating miRNAs [18]. Emerging evidence has indicated that circulating miRNAs are localized in microvesicles or bind to other plasma components such as high-density lipoprotein (HDL) particles and RNA-binding proteins [19, 20]. These circulating miRNAs can enter recipient cells and decrease the protein levels of target genes [21].

\section{Cross-kingdom regulation}

Emerging evidence has uncovered the ability of small non-coding RNAs to transform from one species to other species. Professor Zhang and his team revealed an important function of miRNA: cross-kingdom regulation [22]. Their results revealed that exogenous plant miRNAs could be detected in both tissues and sera from different animals after the oral intake of plants. Subsequently, miRNA-2911, an atypical honeysuckle-encoded miRNA, was found to directly target various influenza A viruses, inhibiting virus replication and ultimately rescuing weight loss in viral infected mice [23]. In 2017, Professor Zhang and coworkers again reported that plant miRNAs enriched in larval beebread regulated the development of honeybee caste [24]. Interestingly, a recent report by Saima et al. suggested the potential cross-kingdom regulation of plant-derived miRNAs and indicated that miRNAs from the parasitic plant Cuscuta campestris could target the mRNAs of host Arabidopsis thaliana, leading to mRNA cleavage, which ultimately inhibited mRNA accumulation [25]. These new modes of cross-species regulation may be involved in symbiotic and pathogenic relationships among different kinds of organisms [26, 27]. 
As mounting reports document that miRNAs work as extensive regulators of various types of physiological activity (e.g., hematopoiesis, tumorigenesis, tumor metastasis, fat metabolism and intestinal mucosal homeostasis), interest in developing miRNA-based medicine has dramatically increased [28-31]. However, the half-life of miRNAs is short because of the presence of nucleases [32]. Moreover, due to their polarity, miRNAs have difficulty passing through the phospholipid bilayer cell membrane; thus, miRNA cannot rapidly penetrate the vascular endothelium and is retained in blood storage organs, including the liver and spleen, and it is ultimately excreted by the kidneys. To solve this problem, a large number of vectors have been developed to deliver miRNAs. Here, we provide novel insight into the promise of miRNA-based therapeutic approaches and the development of viral and nonviral vectors, including therapeutic applications for modified miRNAs and the challenges of vector construction.

\section{Therapeutic approaches involving miRNA}

Usually, naked RNA is highly susceptible to degradation by abundant ribonucleases in the blood and to phagocytosis by the reticuloendothelial system (RES). Chemical modifications can increase the stability of oligonucleotides for in vivo delivery. Antisense oligonucleotide (ASO) technology was introduced for functionally studying miRNA, and the ASOs that are used to silence miRNA are called anti-miRNA oligonucleotides (AMOs) [33]. Chemical modifications include phosphorothioate-containing oligonucleotides, methylphosphonate-containing oligonucleotides, boranophosphate-containing oligonucleotides, 2'-O-methyl-(2'-O-Me) or 2'-O-methoxyethyl oligonucleotides (2'-O-MOE), $2^{\prime}$-fluoro oligonucleotides $\left(2^{\prime}-\mathrm{F}\right)$, locked nucleic acid (LNA) oligonucleotides, peptide nucleic acids (PNAs), phosphorodiamidate morpholino oligomers (PMOs) and other chemical modifications, such as Cy3-, cholesterol-, biotin- and amino-modified oligonucleotides (Fig. 2).

Phosphorothioate-, methylphosphonate-, or borano phosphate-containing oligonucleotides substitute a sulfur, methyl, or borano group, respectively, for the $\alpha$-oxygen of the phosphate, in an attempt to overcome the stability issue [34].

The introduction of a 2'-O-methyl or 2'-O-methoxyethyl group to the ribose moiety of a phosphorothioate oligoribonucleotide dramatically enhances binding stability and protects oligonucleotides from nuclease degradation. 2 '-fluoro-oligoribonucleotides contain a fluorine molecule bound to the 2' -oxygen of the ribose [35].

LNAs are RNA analogs that introduce a $2^{\prime}, 4^{\prime}$ methylene bridge in the ribose to form a bicyclic nucleotide [36]. PNA is an artificially synthesized polymer similar to DNA or RNA that is composed of repeating $\mathrm{N}$-(2-aminoethyl)-glycine units linked by peptide bonds [37]. PMOs contain morpholine rings that are linked through phosphorodiamidate groups [38].

Terminal chemical modifications, including Cy3-, cholesterol-, biotin- and amino-modified oligonucleotides, can increase the stability and tracer function of

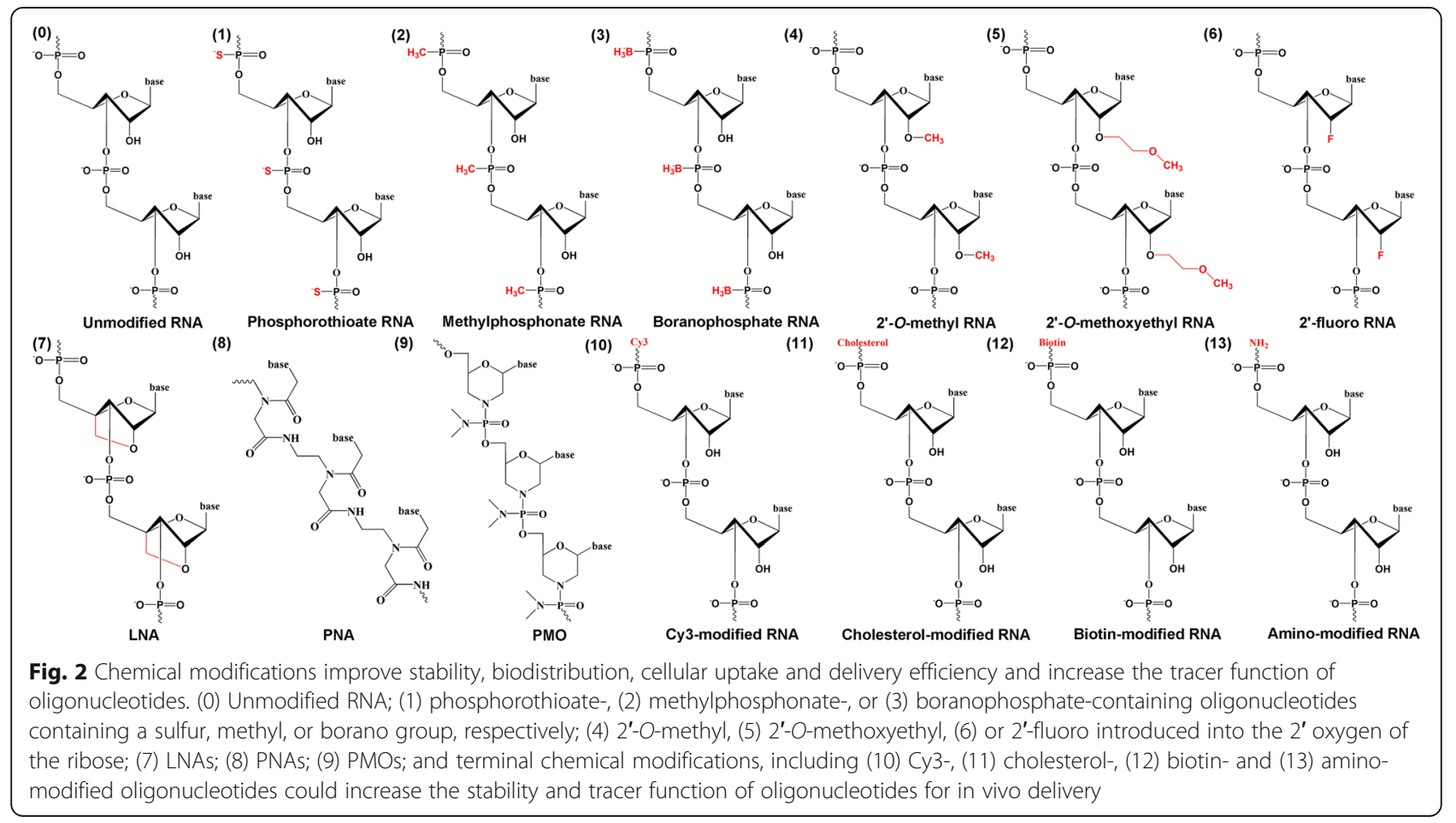


oligonucleotides for in vivo delivery $[39,40]$. In practical applications, multiple modifications are used together to increase the stability, delivery and cellular uptake efficiency of oligonucleotides in vivo.

To change the expression levels of target genes, miRNA-based therapies include the following two types: (a) miRNA suppression therapy when the target gene is downregulated and (b) miRNA replacement therapy when the target gene is downregulated (Fig. 3).

\section{miRNA suppression therapy}

miRNA suppression therapy can remove miRNA suppression of a target mRNA, thus increasing the mRNA expression level. AMOs bind to the miRNA sense strand, block interactions between miRISC and its target mRNA, prevent the degradation of the mRNA, and thus allow the mRNA to be translated. To improve the inhibition efficiency, multiple chemical modifications are applied to enhance the affinity and stability of AMOs, including miRNA inhibitors and miRNA antagomirs.

miRNA inhibitors (also denoted as anti-miRNAs) are single-stranded RNA molecules. These anti-miRNAs can specifically bind to endogenous miRNA and abolish its activity. miRNA inhibitors are mainly used in vitro in combination with Lipofectamine transfection reagent to investigate the biological function of miRNA via "loss-of-function" experiments.

Antagomirs are single-stranded RNA molecules with specific chemical modifications. 2-Phosphorothioates are introduced at the $5^{\prime}$ end and the cholesterol group, and 4-phosphorothioates are introduced at the 3 ' end. Moreover, 2'-methoxy groups are introduced into the full length oligonucleotides [41]. These chemical modifications enhance the stability and cellular uptake efficiency of antagomirs [42]. Therefore, these miRNA antagomirs can be used in vivo via either local or systemic administration to downregulate the corresponding endogenous miRNA levels.

miRNA masks are 22-nt single-stranded oligoribonucleotides with 2'-O-methyl-modifications [43]. Unlike AMOs, a miRNA mask does not directly bind to target miRNA. Instead, the miRNA mask can interact with miRNA binding sites localized in the 3'-UTR of target gene mRNA through a fully complementary mechanism. The miRNA mask approach is an important supplement to AMOs, which are useful for investigating the total biological function of a specific miRNA; however, miRNA masks are more suitable for studying the influence of miRNA on specific pathways containing a target gene.

miRNA sponges are usually plasmid-encoding copies that contain binding sites complementary to the seed region of the target miRNA [44]. After transfection into cells, these plasmids can transcribe high levels of sponge
RNAs that bind to the seed region, which allows them to block a family of miRNAs containing the same seed sequence. As competitive inhibitors, miRNA sponges exhibit similar inhibition efficiency with short nucleotide fragments.

\section{miRNA replacement therapy}

miRNA mimics are synthetic double-stranded miRNA-like RNA molecules that can simulate endogenous miRNAs and bind to target gene mRNA, which ultimately leads to posttranscriptional repression.

miRNA agomirs are artificial double-stranded miRNA mimics with more chemical modifications. The antisense strand of an agomir has the same modification as that of the antagomir. Compared with miRNA mimics, these chemical modifications enhance the stability and activity of miRNA agomirs. Therefore, agomirs can also be used to upregulate their corresponding miRNAs in special tissues and to investigate the biological function of miRNA in vivo.

miRNA precursors (also known as pre-miRNA) are chemically modified single-stranded RNA fragments that are synthesized to simulate mature miRNAs. These miRNA precursors are transfected into cells via a commercial reagent or electroporation similar to siRNAs. After entering cells, miRNA precursors are cleaved by the Dicer enzyme and transformed into mature miRNAs. Therefore, pre-miRNAs can be used to investigate the biological function of miRNA via "gain-of-function" experiments.

miRNA-expressing plasmids can also induce the upregulation of miRNA as they carry a fluorescent reporter that can help investigators verify the expression and localization of miRNA. For example, Takara Bio constructed the pmR-ZsGreen1 and pmR-mCherry vectors, which link a selective miRNA expression cassette with a bright green or red fluorescent reporter gene, respectively.

Although many chemical modifications increase the stability of miRNAs, this effect may not be sufficient for in vivo applications. An efficient delivery system is generally accepted to be essential for developing miRNA-based therapeutics. In this review, we divide vectors into two types: viral vectors (1) and nonviral carriers. Nonviral carriers are divided into six categories: (2) inorganic material-based delivery systems, (3) lipid-based nanocarriers, (4) polymeric vectors/dendrimer-based vectors, (5) cell-derived membrane vesicles and (6) 3D scaffold-based delivery systems (Fig. 4).

\section{Viral vectors for miRNA and anti-miRNA oligonucleotide delivery}

Viral vectors can efficiently transfer genes into target cells. Various viral vectors have been constructed to 


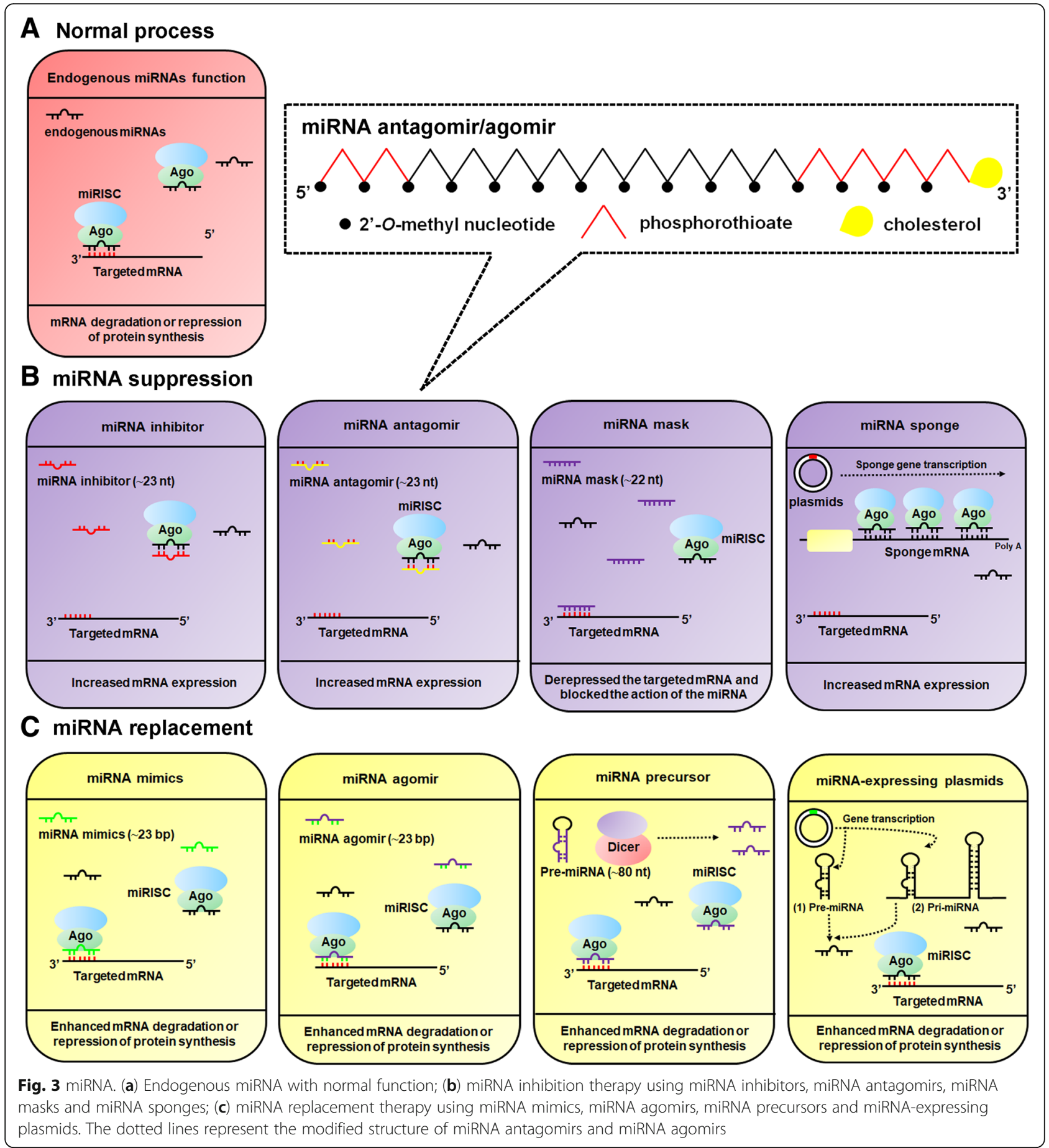

mediate RNA interference (RNAi) because they can transfer genes into different tissues/organs and cause long-term gene expression. As viral vectors possess distinct characteristics, some vectors are more suitable for certain purposes than others. Here, we introduce four widely used viral vectors for miRNA delivery including adenovirus vectors, adeno-associated virus vectors, retroviral vectors, and lentivirus vectors.

\section{Adenoviral vectors}

Adenoviruses (Ad), which are derived from the Adenoviridae family, are nonenveloped viruses that contain linear double-stranded DNA genomes of $\sim 36 \mathrm{~kb}$ in length with two inverted terminal repeats (ITRs) at its termini [45].

To upregulate transgene efficiency and reduce immunogenicity in vivo, all of the viral protein-coding 


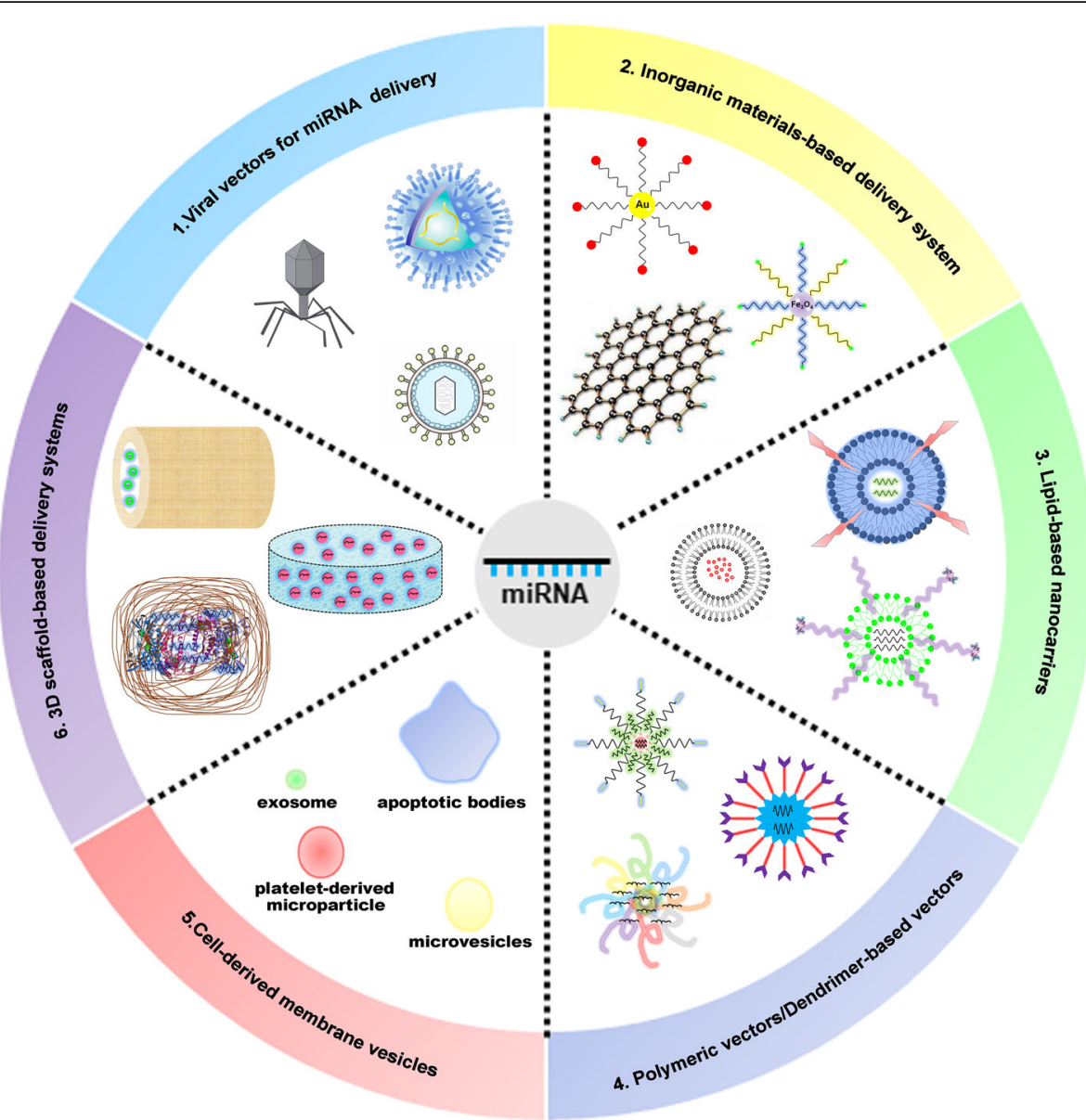

Fig. 4 Different types of vectors used for miRNA delivery. Vectors are divided into two types: viral vectors (1) and nonviral vectors. Nonviral vectors are divided into six categories: (2) inorganic material-based delivery systems, (3) lipid-based nanocarriers, (4) polymeric vectors/dendrimerbased vectors, (5) cell-derived membrane vesicles and (6) 3D scaffold-based delivery systems

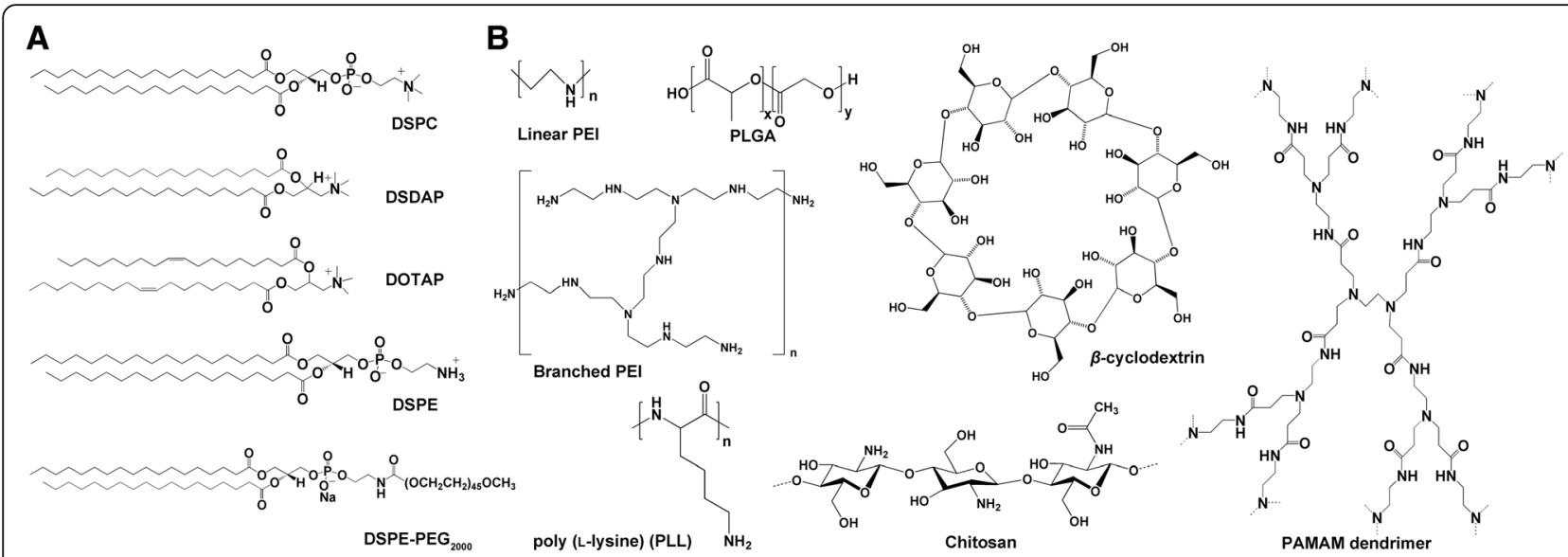

Fig. 5 Chemical structures of different polymers used for miRNA delivery. (a) Structure diagram of different charged lipids (DSDAP, DOTAP, DSPC and DSPE). (b) Structure diagram of polymeric vectors (PLL, PEI, PLGA, chitosan, $\beta$-cyclodextrin and PAMAM) 
sequences were deleted to construct helper-dependent Ad vectors (HD AdVs) [46]. Moreover, the natural hepatotropism of Ad makes it potentially advantageous for liver-targeted gene delivery [47]. HD AdVs are therefore applied to efficiently deliver cassettes encoding primary miRNAs into liver tissue. Recently, Mohube et al. found the short-term blockade of Hepatitis B Virus (HBV) replication in vivo via the expression of anti-HBV pri-miRNA mimics (pri-miRNA-122/5, pri-miRNA-31/5, or pri-miRNA-31/5-8-9) by HD AdVs [48].

Oncolytic adenoviruses are considered suitable vectors for transferring therapeutic genes for tumor immunotherapy due to their commendably tumor-restricted replication abilities [49]. Cheng et al. generated an oncolytic adenoviral vector named AdCN205 to coexpress interleukin-24 (IL-24) and miRNA-34a, and they achieved better antitumor effects in experimental hepatocellular carcinoma (HCC) models [50]. However, the major disadvantage of HD AdVs is their powerful stimulation of host innate and adaptive immune responses, which may limit the widespread use of this vector [50].

\section{Adeno-associated viral vectors}

Adeno-associated viruses (AAV) from the Parvoviridae family are nonenveloped viruses with single-stranded DNA genomes [51]. Sustained gene expression has been observed in different organs of mice after AAV treatment [52]. Recently, Yu Miyazaki and colleagues reported that a novel therapeutic approach based on an AAV vector plasmid encoding miRNA-196a ameliorated spinal and bulbar muscular atrophy (SBMA) symptoms by downregulating Elav-like family member 2 (CELF2) [53].

\section{Retroviral vectors}

Retroviruses (RVs) are enveloped viruses that can carry two copies of a single-stranded RNA [54]. Most retroviral vectors are constructed based on moloney murine leukemia virus (MMLV), which has a simple genome that encodes env, pol and gag and is flanked by long terminal repeats (LTRs) [55]. When a virus infects host cells, double-stranded DNA is formed by the reverse transcriptase enzyme and then integrated into the host genome, which ultimately leads to the persistent expression of the inserted gene fragment [56]. In a recent study, the administration of MMLV encoding miRNA-21 (MMLV-miR-21) significantly improved miRNA-21 expression levels in adult mouse cardiac fibroblasts compared with those of the MMLV-ctrl group [57].

\section{Lentiviral vectors}

Lentiviruses (LVs), which are similar to RVs, can stably insert themselves into the genomes of recipient cells, which leads to sustained gene expression [58]. Recently, evidence emerged that the administration of a lentivirus vector encoding miRNA-133b improved functional recovery in spinal cord-injured mice [59]. In another study, a lentiviral vector-mediated miRNA-101 sponge was prepared, and the intrahippocampal injection of LVs mitigated the overproduction of soluble $\beta$-amyloid precursor protein (sAPP $\beta$ ) in hippocampal neurons [60].

Despite their high delivery efficiency, viral vectors also have disadvantages, including low loading capacity, high toxicity and strong immunogenicity [61]. Therefore, various nonviral vectors have been designed and constructed based on actual needs. Their low toxicity and high biocompatibility make nonviral vectors a useful complement to viral vectors.

\section{Nonviral vectors for miRNA and anti-miRNA oligonucleotide delivery Inorganic material-based delivery systems}

Inorganic materials, including gold nanoparticles (AuNPs), mesoporous silicon, graphene oxide and $\mathrm{Fe}_{3} \mathrm{O}_{4^{--}}$ mediated NPs, are widely used in nanotechnologies and have been developed as vectors to deliver miRNA. Functional groups such as thiol and amino groups can be easily attached to the surface of AuNPs, and these chemically modified AuNPs have been employed as miRNA vehicles [62]. Jia et al. reported the covalent conjugation of thiol-modified antagomir-miRNA-155 to AuNPs, and the administration of miRNA-155-AuNPs via tail vein injection promoted M2 macrophage polarization, reduced inflammatory mediators and ultimately recovered cardiac function in an ovariectomized (OVX) diabetic murine model [63].

Mesoporous silica nanoparticles (MSNs) have several advantages, such as large surface area and pore volume, easy surface modification, thermal stability and favorable biocompatibility. Therefore, MSNs are considered to be promising miRNA carriers [64]. Recently, Li et al. demonstrated that anti-miRNA-155-loaded MSNs could be conjugated to polymerized dopamine (PDA) and the aptamer AS1411 to fabricate a nanocomplex (MSNs-anti-miRNA-155@PDA-Apt) [65]. Treatment with MSNs-anti-miRNA-155@PDA-Apt effectively inhibited tumor growth in a colorectal cancer (CRC) mouse model [65].

Graphene oxide (GO) is widely applied to deliver nucleic acids in vivo. The unique honeycomb network of GO enables it to adsorb nucleobases [66]. In a recent study, researchers developed a Cy3-labeled antisense miRNA-21 PNA probe loaded onto hyaluronic acid (HA)-conjugated GO, and this novel delivery system specifically targeted CD44-positive MBA-MB231 cells and excited fluorescence via interactions with endogenous miRNA-21 [67].

A $\mathrm{Fe}_{3} \mathrm{O}_{4}$-based delivery nanovector was developed for miRNA-100-mediated fibroblast growth factor receptor 
3 (FGFR3) regulation. The nanocomplex, named PMMNCs-miR-100, contained mesoporous magnetic clusters linked by ternary polymers (poly $(\gamma$-glutamic acid) ( $\gamma$-PGA), polyethylenimine (PEI), or polyacrylic acid (PAA)) for delivering miRNA in vivo [68]. Due to its polycation polymer-functionalized mesoporous structure, the miRNA-loading ability and tumor cell uptake efficiency of the nanocomplex were greatly increased [68]. Additionally, systemic administration of PMMNCs-miRNA-100 combined with conventional docetaxel chemotherapy significantly enhanced the antitumor therapeutic effects compared with that of docetaxel alone in FGFR3-mediated patient-derived xenografts (PDXs) [68].

\section{Lipid-based nanocarriers}

Lipids can be easily chemically modified to conjugate with targeting moieties and fluorescent probes. Therefore, lipid-based nanocarriers are widely used for delivering nucleic acids in vivo. Cationic lipids are amphiphilic molecules composed of a hydrophilic head and a hydrophobic tail [69], and they can currently be selected from commercially available products, such as Lipofectamine ${ }^{\circ}$. Many studies have validated the use of cationic liposomes as carriers for transporting miRNA in vivo. At present, a large number of cationic lipids have been synthesized for nucleic acid drug delivery; however, low delivery efficiency is the main obstacle that limits their clinical application. To overcome this obstacle, novel lipids have been synthesized and new methods for constructing lipid nanocomplexes have been developed. Subsequently, polyethylene glycol (PEG), a frequently used functional group, was conjugated to cationic lipids to escape phagocytosis of the RES when administered systemically [70].

Recently, a report by Tokyo University researchers demonstrated that miRNA-126-loaded PEG-modified liposomes combined with entrap ultrasound (named "bubble liposomes") promote angiogenesis and improved blood flow in an experimental hindlimb ischemia model [71]. Using the reversed-phase evaporation method, bubble liposomes were synthesized using 1,2-distearoyl-sn-glycero-phosphatidylcholine (DSPC), 1,2-distearoyl-3dimethylammonium-propane (DSDAP) and 1,2-distearoylphosphatidylethanolamine-methoxy-polyethylene glycol (PEG $\left.{ }_{2000}\right)$ (Fig. 5a). Then, the liposome suspension was pressurized with perfluoropropane gas (an echo-contrast gas) and placed in a bath sonicator, eventually forming bubble liposomes [71].

In another study, Zhang et al. constructed a novel system containing miRNA-10b antagomirs and paclitaxel via a $\mathrm{pH}$-responsive liposome modified with the antimicrobial peptide [D]- $\mathrm{H}_{6} \mathrm{~L}_{9}$ (D-Lip) that could delay 4 T1 tumor growth and reduce lung metastases in a murine breast cancer model [72]. Using the thin film hydration approach, these novel liposomes were assembled with the 1,2-dioleoyl-3-trimethylammonium-propane (DOTAP), soybean phosphatidylcholine (SPC), DSPE-PEG ${ }_{2000}-[D]-\mathrm{H}_{6} \mathrm{~L}_{9}$ and DSPE-PEG 2000 (Fig. 5a).

\section{Polymeric vectors}

Polyethylenimines (PEIs) are rich in amine groups and are positively charged. Thus, they can bind to small RNAs to form nanosized complexes, which prevent RNA degradation and promote cellular uptake and intracellular release [73] (Fig. 5b). At present, branched or linear PEIs with different molecular weights ranging from $100 \mathrm{Da}$ to approximately $1000 \mathrm{kDa}$ can be purchased [74]. Previous studies have shown that branched $25 \mathrm{kDa}$ PEIs were more effective at transferring mmu-miRNA-494-3p into mouse embryonic fibroblast (MEF) cells than Lipofectamine 2000 [75]. Huang et al. and Shi et al. proved that complexes of branched PEIs $(25 \mathrm{kDa})$ with the miRNA-141 precursor or the miRNA-31 precursor could significantly enhance colon tissue miRNA-141 or miRNA-31 expression levels, respectively, through intracolonic administration [76, 77].

Due to its toxicity, the application of PEI is limited in current clinical research. PEG, a non-ionic and hydrophilic polymer, can impair the toxicity of PEI when covalently linked to it. A large number of studies have confirmed that PEGylation enhances the biocompatibility of delivery systems based on PEI. Recently, research was reported in which PEG/PEI nanoparticles were employed as a nonviral vector for miRNA-150 transfection, and these nanoscale complexes addressed the issue of poor transfection efficiency and instability in human leukemia cells [78]. In addition to PEG, other polymers such as poly(L-lysine) (PLL) can also be used for PEI modification (Fig. 5b). Gao et al. indicated that a PEI-PLL/miRNA-21 sponge or PEI-PLL/anti-miRNA-21 treatment could effectively reduce miRNA-21 levels in MCF-7 cells [79].

As an FDA approved biomaterial, poly(lactide-co-glycolide) (PLGA) is a copolymer of poly lactic acid (PLA) and poly glycolic acid [80] (Fig. 5b). Due to its favorable biocompatibility and well-documented utility for sustained drug release, PLGA has been frequently used in the clinic. PLGA NPs are taken up by cells via endocytosis, and the loading drug is released inside cells. Nucleic acid drug delivery systems based on PLGA NPs have improved therapeutic effects due to their excellent drug release properties. Previous studies have shown that treatment with nanoparticles composed of monomethoxy PEG, PLGA, PLL, lactobionic acid, vascular endothelial growth factor antibodies and has-miRNA-99a mimics could suppress tumor growth in an experimental HCC model [81]. 
Chitosan is a linear molecule with randomly distributed $\beta$ - $(1 \rightarrow 4)$-linked D-glucosamine and N-acetyl-D-glucosamine [82] (Fig. 5b). As a natural biocompatible and mucoadhesive polysaccharide, chitosan has little cytotoxicity and can prevent nucleic acid degradation. Macrophages express high levels of galactose/ $\mathrm{N}$-acetylgalactosamine-specific lectin (MGL), which can mediate endocytosis [83]. Therefore, galactosylated low molecular weight chitosan (G-LMWC) is synthesized using chitosan and lactic acid for targeting macrophages [84-86]. Zou et al. developed a colonic macrophage-targeted nucleic acid delivery system based on the G-LMWC/ASO nanocomplex [87]. Huang et al. reported that G-LMWC combined with miRNA-16 precursors increased colonic macrophage miRNA-16 levels and alleviated the colitis symptoms of 2,4,6-trinitrobenzene sulfonic acid (TNBS)-treated mice through intracolonical injection [88].

$\beta$-cyclodextrin is composed of homogeneous cyclic $\alpha 1,4$-linked D-glucopyranose units in a seven-member ring [89] (Fig. 5b). $\beta$-carbohydrate-based polymers have been used to enhance the efficiency of miRNA delivery systems. Recently, Zeng et al. constructed a novel delivery vector composed of miRNA-34a mimics and matrix metalloproteinase-2 (MMP2)-cleavable substrate peptides [90]. In this system, enzyme-cleavable PEG derivatives are linked to cationic $\beta$-cyclodextrin/PEI, decreasing the cytotoxicity of PEI and condensing the therapeutic cargos, which resulted in excellent tumor targeting capability and antitumor activity in $4 \mathrm{~T} 1$ xenograft tumor models [90].

Polymeric micelles are obtained by linking a hydrophilic polymer with a hydrophobic polymer. The most widely used hydrophilic polymers contain PEG, poly (L-amino acids), poly (propylene glycol), biodegradable polyesters and phospholipids, polyorthoesters, and long-chain fatty acids [91]. Recently, researchers designed a novel dual stimulus-sensitive mixed polymeric micelles codelivery system for the delivery of the doxorubicin and endogenous tumor suppressor miRNA-34a into cancer cells [92]. Two stimulus-sensitive components, an MMP2-repsonsive doxorubicin conjugate and a glutathione-responsive miRNA-34a conjugate, were assembled to form single NPs and then linked with PEG for long-term blood circulation and with cell-penetrating peptide (CPP)-TATp to improve intracellular uptake in a 3D spheroid model of tumor mass [92].

\section{Dendrimer-based vectors}

Dendrimers are three-dimensional, hyperbranched globular nanopolymeric materials. Due to their narrow polydispersity index and modification with multiple functional groups, dendrimers have unique advantages compared with other polymers and are widely used in different fields [93].
PAMAM dendrimers were the first synthetic polymers with dendritic structures. Through a divergent method, PAMAM dendrimers were developed from ethylenediamine or ammonia initiator core reagents [94]. Due to the positive charge on their surface, PAMAM dendrimers can condense nucleic acid molecules. Unlike undegradable PEI, PAMAM dendrimers are biodegradable polymers that exhibit relatively low genotoxicity and cytotoxicity.

Recently, Wang et al. demonstrated a novel carrier denoted as NGO-PEG-dendrimers for miRNA delivery. NGO-PEG-dendrimers/anti-miRNA-21 were fabricated by conjugating PAMAM dendrimers and PEG-functionalized nanographene oxide (NGO) to 2'-O-methyl-modified anti-miRNA-21 [95]. The intravenous injection of NGO-PEG-dendrimers/anti-miRNA-21 caused a remarkable increase in bioluminescence signals within tumor areas through a luciferase reporter [95].

\section{Cell-derived membrane vesicles}

Distant intercellular communication is crucial for the maintenance of cellular environmental homeostasis in multicellular organisms. Recent reports have shown that distant cell-to-cell communication also occurs via extracellular vesicles (EVs) [96]. EVs are considered important factors involved in intercellular communication and are also used as biomarkers and drug carriers [97].

Wang et al. reported that AS1411, DNA aptamermodified EVs-loaded with Cy5-labeled let-7, could effectively accumulate in tumor tissues and suppress tumor growth when injected intravenously [98]. In another study, researchers demonstrated that the systemic administration of brain metastatic cancer cell-derived EVs containing miRNA-181c promoted brain metastasis and destruction of the blood-brain barrier (BBB) [99].

Based on their molecular profiles and intracellular origins, three main types of EVs are typically found: exosomes, microvesicles and apoptotic bodies. Exosomes are nanoscale vesicles that contribute to intercellular communication, antigen presentation and RNA shuttling (mainly mRNA and miRNA). These membrane vesicles (40-120 $\mathrm{nm}$ in diameter) are derived from late endosomes [100]. Emerging data suggests that exosomes could mediate intercellular communication through the transfer of bioactive molecules such as miRNAs and the protection of encapsulated small RNAs from ribonucleases (RNases) in bodily fluids [101]. Recently, Lee et al. developed a novel single-step in situ detection method for exosome miRNAs using a nanosized fluorescent oligonucleotide probe they called a-"molecular beacon" [102].

Additionally, exosomes have low cytotoxicity and negligible antigenicity. Therefore, they are ideal vehicles for nucleic acid drugs. As they can circumvent endocytosis 
and escape from phagocytosis by the RES, exosomes have high delivery efficacy. In a recent study, endothelial progenitor cell-derived exosomes containing abundant miRNA-126-3p and 5p could attenuate organ injury and vascular permeability in cecal ligation and puncture (CLP)-induced sepsis [103]. In another study, Wen et al. utilized human bone marrow mesenchymal stem cells (hBMSCs) and their exosomes (which are rich in siFas and anti-miRNA-375) to restrain islet apoptosis and primary nonfunction (PNF) during islet transplantation in humanized NOD scid gamma (NSG) mice [104]. However, the large-scale production of exosomes is not easily available due to cost. An interesting study showed that bovine milk could be used as a scalable source of exosomes that might act as carriers for miRNA delivery [105].

Microvesicles (MVs, or shedding vesicles) (100-1000 $\mathrm{nm}$ in size) are vesicles that are shed from multiple cell types during certain pathological and physiological states [106]. In a recent study, BMSCs were infected with a miRNA-200b-expressing lentivirus, and MVs were isolated through a differential centrifugation method. The collected MVs were subsequently used to treat TNBS-induced rat intestinal fibrosis [107]. Zhang et al. demonstrated the suppressive effect of MVs containing miRNA-29a/c on tumor growth in gastric cancer (GC) [108]. Recently, a report by Cui et al. proved that leukemia cell-derived MVs could induce T cell exhaustion by delivering multiple functional miRNAs [109].

Platelets, which are derived from bone marrow megakaryocytes, are fragments with a diameter of 1 to $4 \mu \mathrm{m}$ that are responsible for the maintenance of vascular integrity and physiology hemostasis [110]. In some cases, activated platelets can release microparticles (MPs) (a type of MV), which are small EVs that range from 0.1 to $1 \mu \mathrm{m}$ in size and are from the cytoplasmic membrane [111]. John et al. illustrated that Ago2/miRNA-223 complex-laden platelet-derived cargos could easily enter human umbilical vein endothelial cells (HUVECs) [111]. Subsequently, Liang et al. further elaborated that plateletderived MVs containing high levels of miRNA-223 could promote lung cancer cell invasion by reducing the level of tumor suppressor EPB41L3 [112].

Apoptotic bodies are characteristic membrane blebs that are released from apoptotic cells. Apoptotic bodies have the widest spread diameter, which can range from approximately $50-5000 \mathrm{~nm}$ [113]. As they express "eat-me" molecules (e.g., phosphatidylserine), apoptotic bodies can recruit phagocytes to nearby apoptotic cells, leading to their clearance [114]. Research has demonstrated that endothelial cell-derived apoptotic bodies containing high levels of miRNA-126 can trigger the secretion of chemokine (C-X-C motif) ligand-12 (CXCL12), recruit multiple progenitor cells and protect mice from atherosclerosis [115].

\section{D scaffold-based delivery systems}

With favorable spatiotemporal control and mechanical barriers circumventions, 3D biomaterial scaffolds can efficiently maintain the therapeutic effects of miRNA. At present, various 3D-scaffold types have been developed for miRNA delivery, including hydrogels, electrospun fibers, and other more abundantly porous or spongy 3D-scaffolds.

Hydrogels are polymer networks with hydrophilic properties. Researchers have demonstrated that PEGylation hydrogels constantly release siRNA against noggin and miRNA-20a mimics and promote encapsulated human bone marrow-derived mesenchymal stem cells (hMSCs) to differentiate into osteoblasts [116]. In another study, scientists from the Massachusetts Institute of Technology (MIT) showed that a novel self-assembled dual-color RNA-triple-helix hydrogel composed of miRNA-225 mimics and miRNA-221 antagomirs facilitated nearly $90 \%$ tumor shrinkage in a triple-negative breast cancer mouse model [117].

Due to their versatility, electrospun fibers are being explored for use in many different applications. To target the delivery of miRNA-126 mimics into vascular endothelial cells (VECs), researchers recently developed a bilayer vascular scaffold fabricated by target carriers and electrospun fibrous membranes [118]. The outer layer of poly(E-caprolactone) (PCL) and gelatin contributed to mechanical stability, and the inner layer of poly(ethylene glycol)- $b$ poly(L-lactide-co-e-caprolactone) (PELCL), which contained complexes of miRNA-126 mimics in REDV peptide-modified trimethyl chitosan-g-poly(ethylene glycol), regulated the response mediated by VECs [118].

Recently, Zhang et al. demonstrated that a novel hyperbranched polymer (HP) with high miRNA-26-binding ability could self-assemble into nanoscale complexes [119]. Such an engineered 3D-scaffold was able to induce the regeneration of calvarial bone defects in an osteoporotic mouse model [119]. Irene et al. reported an interesting collagen-nanohydroxyapatite miRNA-activated scaffold for tissue engineering that could efficiently deliver both miRNA antagomirs and miRNA mimics to human mesenchymal stem cells [120].

\section{Progress in clinical research on miRNAs as nucleic acid drugs}

To date, many miRNA-based therapeutics have been used in clinical trials (https://clinicaltrials.gov/ct2/home). Miravirsen (SPC3649) (Clinical Trials.gov Identifier: NCT02452814), the world's first miRNA drug candidate, which is currently in clinical testing, was applied to treat hepatitis C in Phase II clinical trials in 2017. Miravirsen is composed of LNA ribonucleotides whose sequences are complementary to miRNA-122 [121]. RG-101, which is in a Phase $1 \mathrm{~b}$ clinical trial, is a chemically modified 
phosphorothioate oligonucleotide inhibitor that targets miRNA-122; it is conjugated to a multivalent $\mathrm{N}$-acetylgalactosamine carbohydrate structure that was designed to enhance uptake via binding to the asialoglycoprotein receptor on hepatocytes. However, RG-101 has been placed on clinical hold as a result of two serious adverse events (SAE) of jaundice. MRX34 (Clinical Trials.gov Identifier: NCT01829971), a liposome-encapsulated miRNA34a mimic, was used for patients with advanced solid tumors in a multicenter Phase I trial. Despite its therapeutic effects, the clinical program was terminated due to immune-related adverse events. MesomiR-1 (Clinical Trials.gov Identifier: NCT02369198), a miRNA-16-based miRNA mimic encapsulated in nonliving bacterial minicells with an anti-EGFR bispecific antibody, was applied for mesothelioma and non-small-cell lung cancer (NSCLC) in a Phase I study. MRG-106 (Clinical Trials.gov Identifier: NCT02580552), an anti-miRNA-155 LNA-modified antisense inhibitor, was employed for patients with cutaneous $\mathrm{T}$ cell lymphoma and mycosis fungoides in a Phase II potentially registrational clinical trial. MRG-201 (Clinical Trials. gov Identifier: NCT02603224), a miRNA-29 mimic with a cholesterol-conjugated miRNA duplex, was used for patients with scleroderma, and the initiation of a Phase II clinical trial was announced. RG-125/AZD4076 (Clinical Trials.gov Identifier: NCT02612662), an anti-miRNA-103/ 107 conjugated with $N$-acetylgalactosamine (GalNAc), was used in patients with non-alcoholic fatty liver and type 2 diabetes in a Phase I/II trial. Because extracellular miRNA can be easily separated from patient biological fluids, it is an ideal biomarker candidate for the diagnosis and prognosis of disease. For example, miRNA $7^{\text {ta }}$ is the first approved commercially available kit for liver cancer diagnosis via the detection of 7 miRNAs.

\section{Conclusions}

Numerous miRNA-based delivery systems have been constructed and used to obtain favorable effects in application. Current research on miRNA-based therapeutics depends mainly on the ability of delivery cargos to protect oligonucleotides from serum RNase degradation, to improve targeting ability and to enhance therapeutic effects without triggering immune-related adverse effects. In most studies, intravenous injection or local treatment was the main method of administration for in vivo miRNA delivery. Very few studies have used oral administration for miRNA-based delivery.

Chemical modification and vehicle complexation have been explored to stabilize RNAs, but RNA stability does not increase cellular uptake and escape. Both viral and nonviral vectors have disadvantages, including immunogenicity and low oligonucleotide-loading capacity. When administered systemically, such nanocargos can be easily retained in the liver and spleen and quickly eliminated by the kidney. The targeting ability and long-term blood circulation of miRNA-based delivery systems should be improved to increase delivery efficiency. Therefore, new biomaterials should be synthesized and new methods should be developed for delivery systems. Emerging evidence has demonstrated that cell-derived membrane vesicles (e.g., exosomes, microvesicles and apoptotic bodies) might act as ideal delivery vectors due to their low cytotoxicity and negligible antigenicity. More importantly, a deeper and clearer understanding of the biological functions of such systems is imperative.

\section{Abbreviations}

2'-F: 2'-fluoro oligonucleotide; 2'-O-Me: 2'-O-methyl-oligonucleotide; 2'-OMOE: 2'-O-methoxyethyl oligonucleotide; 3'-UTR: 3'-untranslated region; AAV: Adeno-associated virus; Ad: Adenovirus; AMO: Anti-miRNA oligonucleotide; ASO: Antisense oligonucleotide; AuNP: Gold nanoparticle; BBB: Blood-brain barrier; BMSCs: Bone marrow mesenchymal stem cells; CELF2: Elav-like family member 2; CLP: Cecal ligation and puncture; CPP: Cellpenetrating peptide; CRC: Colorectal cancer; CXCL12: Chemokine (C-X-C motif) ligand-12; DOTAP: 1,2-dioleoyl-3-trimethylammonium-propane; DSDAP: 1,2-distearoyl-3-dimethylammonium-propane; DSPC: 1,2-distearoylsn-glycero-phosphatidylcholine; DSPE: 1,2-distearoyl-sn-glycero-3-phosphoryl ethanolamine; EV: Extracellular vesicle; FGFR3: Fibroblast growth factor receptor 3; GalNAc: N-acetylgalactosamine; GC: Gastric cancer; G-

LMWC: Galactosylated low molecular weight chitosan; GO: Graphene oxide; HA: Hyaluronic acid; hBMSC: Human bone marrow mesenchymal stem cell; HBV: Hepatitis B Virus; HCC: Hepatocellular carcinoma; HD Ad: Helperdependent Ad; HD AdV: Helper-dependent adenoviral vector; HDL: Highdensity lipoprotein; hMSC: Human bone marrow-derived mesenchymal stem cell; HP: Hyperbranched polymer; HUVEC: Human umbilical vein endothelial cell; IL-24: Interleukin-24; ITR: Inverted terminal repeat; LNA: Locked nucleic acid oligonucleotide; LTR: Long terminal repeat; LVs: Lentivirus; MEF: Mouse embryonic fibroblast; miRISC: miRNA-induced silencing complex; miRNAs: microRNAs; MMLV: Moloney murine leukemia virus; MMP2: Matrix metalloproteinase-2; MP: Microparticle; MSNs: Mesoporous silica nanoparticles; MV: Microvesicle; NSCLC: Non-small-cell lung cancer; NSG: NOD scid gamma; PDX: Patient-derived xenograft; PEG: Polyethylene glycol; PEG 2000 : 1,2-distearoylphosphatidylethanolamine- methoxypolyethylene glycol; PEI: Polyethylenimine; PEI-PLL: Poly (L-lysine)-modified PEl; PLGA: Poly(lactide-co-glycolide; PMOs: Phosphorodiamidate morpholino oligomers; PNAs: Peptide nucleic acids; PNF: Primary nonfunction; primiRNA: Primary miRNA; PTX: Paclitaxel; RES: Reticuloendothelial system; RV: Retrovirus; SAE: Serious adverse event; SAPP $\beta$ : Soluble $\beta$-amyloid precursor protein; SBMA: Spinal and bulbar muscular atrophy; siFas: siRNA against Fas receptor; SPC: Soybean phosphatidylcholine; TNBS: 2,4,6-trinitrobenzene sulfonic acid; Treg: T cell regulatory; VEC: Vascular endothelial cell;

VEGF: Vascular endothelial growth factor

\section{Acknowledgements}

Not applicable.

\section{Funding}

This work was supported by the National Natural Science Foundation of China (31571458, 31771550, 31400671, J1103512, J1210026 and 31870821).

Availability of data and materials Not applicable.

\section{Authors' contributions}

YF performed the literature analysis and wrote the paper. $\mathrm{ZH}$ and JC supervised the analysis and corrected the manuscript. All authors read and approved the final manuscript.

Ethics approval and consent to participate Not applicable. 


\section{Consent for publication}

Not applicable.

\section{Competing interests}

The authors declare that they have no competing interests.

\section{Publisher's Note}

Springer Nature remains neutral with regard to jurisdictional claims in published maps and institutional affiliations.

\section{Author details}

'State Key Laboratory of Pharmaceutical Biotechnology, School of Life Sciences, Nanjing University, Nanjing 210093, Jiangsu, China. ${ }^{2}$ State Key Laboratory of Analytical Chemistry for Life Sciences and Collaborative Innovation Center of Chemistry for Life Sciences, Nanjing University, Nanjing 210093, Jiangsu, China.

\section{Received: 14 August 2018 Accepted: 14 March 2019 \\ Published online: 05 August 2019}

\section{References}

1. Bartel DP. MicroRNAs: genomics, biogenesis, mechanism, and function. Cell. 2004:116(2):281-97.

2. He L, Hannon GJ. MicroRNAs: small RNAs with a big role in gene regulation Nat Rev Genet. 2004:5:522.

3. Wienholds E, Kloosterman WP, Miska E, Alvarez-Saavedra E, Berezikov E, de

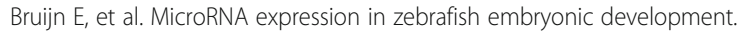
Science. 2005;309(5732):310-1.

4. O'Connell RM, Rao DS, Chaudhuri AA, Baltimore D. Physiological and pathological roles for microRNAs in the immune system. Nat Rev Immunol. 2010;10(2):111-22.

5. Lu J, Getz G, Miska EA, Alvarez-Saavedra E, Lamb J, Peck D, et al. MicroRNA expression profiles classify human cancers. Nature. 2005;435(7043):834-8.

6. Iwasaki YW, Siomi H. miRNA regulatory ecosystem in early development Mol Cell. 2014;56(5):615-6.

7. Jeang KT. RNAi in the regulation of mammalian viral infections. BMC Biol. 2012;10:58.

8. Rottiers $\mathrm{V}$, Naar AM. MicroRNAs in metabolism and metabolic disorders. Nat Rev Mol Cell Biol. 2012;13(4):239-50.

9. Lee RC, Feinbaum RL, Ambros V. The C. elegans heterochronic gene lin-4 encodes small RNAs with antisense complementarity to lin-14. Cell. 1993; 75(5):843-54.

10. Wightman B, Ha I, Ruvkun G. Posttranscriptional regulation of the Heterochronic gene Lin-14 by Lin-4 mediates temporal pattern-formation in C-Elegans. Cell. 1993;75(5):855-62.

11. Hammond SM. An overview of microRNAs. Adv Drug Deliv Rev. 2015;87:3-14.

12. Lim LP, Lau NC, Garrett-Engele P, Grimson A, Schelter JM, Castle J, et al. Microarray analysis shows that some microRNAs downregulate large numbers of target mRNAs. Nature. 2005:433(7027):769-73.

13. Olsen PH, Ambros V. The lin-4 regulatory RNA controls developmental timing in Caenorhabditis elegans by blocking LIN-14 protein synthesis after the initiation of translation. Dev Biol. 1999;216(2):671-80.

14. Vasudevan S, Tong YC, Steitz JA. Switching from repression to activation: MicroRNAs can up-regulate translation. Science. 2007:318(5858):1931-4.

15. Cheng WT, Rosario R, Muthukaruppan A, Wilson MK, Payne K, Fong PC, et al. MicroRNA profiling of ovarian granulosa cell tumours reveals novel diagnostic and prognostic markers. Clin Epigenetics. 2017;9:72.

16. $\mathrm{Xu}$ L, Hu Y, Cao Y, Li J, Ma L, Li Y, et al. An expression atlas of miRNAs in Arabidopsis thaliana. Sci China Life Sci. 2018;61(2):178-89.

17. Lawrie $\mathrm{CH}$, Gal S, Dunlop HM, Pushkaran B, Liggins AP, Pulford K, et al. Detection of elevated levels of tumour-associated microRNAs in serum of patients with diffuse large B-cell lymphoma. Br J Haematol. 2008;141(5):672-5.

18. Chen $X, B a$ Y, Ma L, Cai X, Yin Y, Wang K, et al. Characterization of microRNAs in serum: a novel class of biomarkers for diagnosis of cancer and other diseases. Cell Res. 2008:18(10):997-1006.

19. Vickers KC, Palmisano BT, Shoucri BM, Shamburek RD, Remaley AT. MicroRNAs are transported in plasma and delivered to recipient cells by high-density lipoproteins. Nat Cell Biol. 2011;13(4):423-33.

20. Skog J, Wurdinger T, van Rijn S, Meijer DH, Gainche L, Sena-Esteves M, et al. Glioblastoma microvesicles transport RNA and proteins that promote tumour growth and provide diagnostic biomarkers. Nat Cell Biol. 2008; 10(12):1470-U209.

21. Jung HJ, Suh Y. Circulating miRNAs in ageing and ageing-related diseases. J Genet Genomics. 2014:41(9):465-72.

22. Zhang L, Hou D, Chen X, Li D, Zhu L, Zhang Y, et al. Exogenous plant MIR168a specifically targets mammalian LDLRAP1: evidence of crosskingdom regulation by microRNA. Cell Res. 2012;22(1):107-26.

23. Zhou Z, Li XH, Liu JX, Dong L, Chen Q, Liu JL, et al. Honeysuckle-encoded atypical microRNA2911 directly targets influenza a viruses. Cell Res. 2015; 25(1):39-49.

24. Zhu KA, Liu MH, Fu Z, Zhou Z, Kong Y, Liang HW, et al. Plant microRNAs in larval food regulate honeybee caste development. Plos Genet. 2017;13(8): e1006946.

25. Shahid S, Kim G, Johnson NR, Wafula E, Wang F, Coruh C, et al. MicroRNAs from the parasitic plant Cuscuta campestris target host messenger RNAs. Nature. 2018;553(7686):82-5.

26. Liang $\mathrm{H}$, Zen $\mathrm{K}$, Zhang J, Zhang $\mathrm{CY}$, Chen $\mathrm{X}$. New roles for microRNAs in cross-species communication. RNA Biol. 2013;10(3):367-70.

27. Chin AR, Fong MY, Somlo G, Wu J, Swiderski P, Wu XW, et al. Crosskingdom inhibition of breast cancer growth by plant miR159. Cell Res. 2016:26(2):217-28

28. Hong $\mathrm{SH}$, Kim KS, Oh $H_{\text {. }}$. Concise review: exploring miRNAs-toward a better understanding of hematopoiesis. Stem Cells. 2015;33(1):1-7.

29. Fang YX, Gao WQ. Roles of microRNAs during prostatic tumorigenesis and tumor progression. Oncogene. 2014;33(2):135-47.

30. Nguyen HTT, Dalmasso G, Muller S, Carriere J, Seibold F, Darfeuille-Michaud A. Crohn's disease-associated adherent invasive Escherichia coli modulate levels of microRNAs in intestinal epithelial cells to reduce autophagy. Gastroenterology. 2014;146(2):508-19.

31. Xu Y, Zalzala M, Xu J, Li Y, Yin L, Zhang Y. A metabolic stress-inducible miR34a-HNF4alpha pathway regulates lipid and lipoprotein metabolism. Nat Commun. 2015;6:7466.

32. Czauderna F, Fechtner M, Dames S, Aygun H, Klippel A, Pronk GJ, et al. Structural variations and stabilising modifications of synthetic siRNAs in mammalian cells. Nucleic Acids Res. 2003;31(11):2705-16.

33. Zhang B, Farwell MA. microRNAs: a new emerging class of players for disease diagnostics and gene therapy. J Cell Mol Med. 2008;12(1):3-21.

34. Sharma VK, Watts JK. Oligonucleotide therapeutics: chemistry, delivery and clinical progress. Future Med Chem. 2015;7(16):2221-42.

35. Bernardo BC, Ooi JY, Lin RC, McMullen JR. miRNA therapeutics: a new class of drugs with potential therapeutic applications in the heart. Future Med Chem. 2015;7(13):1771-92

36. Chabot S, Orio J, Castanier R, Bellard E, Nielsen SJ, Golzio M, et al. LNAbased oligonucleotide electrotransfer for miRNA inhibition. Mol Ther. 2012:20(8):1590-8

37. Bertucci A, Prasetyanto EA, Septiadi D, Manicardi A, Brognara E, Gambari R, et al. Combined delivery of Temozolomide and anti-miR221 PNA using mesoporous silica nanoparticles induces apoptosis in resistant glioma cells. Small. 2015:11(42):5687-95.

38. Lennox KA, Behlke MA. Chemical modification and design of anti-miRNA oligonucleotides. Gene Ther. 2011;18(12):1111-20.

39. Guo YE, Steitz JA. 3'-biotin-tagged microRNA-27 does not associate with Argonaute proteins in cells. RNA. 2014;20(7):985-8.

40. Shingara J, Keiger K, Shelton J, Laosinchai-Wolf W, Powers P, Conrad R, et al. An optimized isolation and labeling platform for accurate microRNA expression profiling. RNA. 2005;11(9):1461-70.

41. Krutzfeldt J, Kuwajima S, Braich R, Rajeev KG, Pena J, Tuschl T, et al. Specificity, duplex degradation and subcellular localization of antagomirs. Nucleic Acids Res. 2007;35(9):2885-92

42. Krutzfeldt J, Rajewsky N, Braich R, Rajeev KG, Tuschl T, Manoharan M, et al. Silencing of microRNAs in vivo with 'antagomirs'. Nature. 2005;438(7068): $685-9$.

43. Wang Z. The principles of MiRNA-masking antisense oligonucleotides technology. Methods Mol Biol. 2011:676:43-9.

44. Kluiver J, Slezak-Prochazka I, Smigielska-Czepiel K, Halsema N, Kroesen BJ, van den Berg A. Generation of miRNA sponge constructs. Methods. 2012;58(2):113-7.

45. Douglas JT. Adenoviral vectors for gene therapy. Mol Biotechnol. 2007;36(1):71-80.

46. Maione D, Della Rocca C, Giannetti P, D'Arrigo R, Liberatoscioli L, Franlin LL, et al. An improved helper-dependent adenoviral vector allows persistent 
gene expression after intramuscular delivery and overcomes preexisting immunity to adenovirus. Proc Natl Acad Sci U S A. 2001;98(11):5986-91.

47. Crowther C, Mowa B, Arbuthnot P. Hepatic delivery of artificial micro RNAs using helper-dependent adenoviral vectors. In: Shum K, Rossi J, editors. SiRNA delivery methods: methods and protocols. New York: Springer New York; 2016. p. 249-60.

48. Mowa MB, Crowther C, Ely A, Arbuthnot P. Inhibition of hepatitis B virus replication by helper dependent adenoviral vectors expressing artificial antiHBV pri-miRs from a liver-specific promoter. Biomed Res Int. 2014;2014:718743.

49. Bressy C, Benihoud K. Association of oncolytic adenoviruses with chemotherapies: an overview and future directions. Biochem Pharmacol. 2014;90(2):97-106.

50. Lou W, Chen Q, Ma L, Liu J, Yang Z, Shen J, et al. Oncolytic adenovirus coexpressing miRNA-34a and IL-24 induces superior antitumor activity in experimental tumor model. J Mol Med (Berl). 2013;91(6):715-25.

51. Mezzina M, Merten OW. Adeno-associated viruses. Methods Mol Biol. 2011; 737:211-34.

52. Jooss K, Chirmule N. Immunity to adenovirus and adeno-associated viral vectors: implications for gene therapy. Gene Ther. 2003;10(11):955-63.

53. Miyazaki Y, Adachi H, Katsuno M, Minamiyama M, Jiang YM, Huang Z, et al. Viral delivery of miR-196a ameliorates the SBMA phenotype via the silencing of CELF2. Nat Med. 2012;18(7):1136-41.

54. Pages JC, Bru T. Toolbox for retrovectorologists. J Gene Med. 2004;6(Suppl 1):S67-82

55. Yu YE, Choe W, Zhang WG, Stoica G, Wong PKY. Development of pathological lesions in the central nervous system of transgenic mice expressing the env gene of ts1 Moloney murine leukemia virus in the absence of the viral gag and pol genes and viral replication. J Neuro-Oncol. 1997;3(4):274-82.

56. Liu YP, Berkhout B. miRNA cassettes in viral vectors: problems and solutions. Biochim Biophys Acta. 2011;1809(11-12):732-45.

57. Ramanujam D, Sassi Y, Laggerbauer B, Engelhardt S. Viral vector-based targeting of miR-21 in cardiac nonmyocyte cells reduces pathologic remodeling of the heart. Mol Ther. 2016;24(11):1939-48.

58. Sakuma T, Barry MA, Ikeda Y. Lentiviral vectors: basic to translational. Biochem J. 2012:443(3):603-18.

59. Theis T, Yoo M, Park CS, Chen J, Kugler S, Gibbs KM, et al. Lentiviral delivery of miR-133b improves functional recovery after spinal cord injury in mice. Mol Neurobiol. 2017;54(6):4659-71.

60. Barbato C, Pezzola S, Caggiano C, Antonelli M, Frisone P, Ciotti MT, et al. A lentiviral sponge for miR-101 regulates RanBP9 expression and amyloid precursor protein metabolism in hippocampal neurons. Front Cell Neurosci. 2014;8:37.

61. Vannucci L, Lai M, Chiuppesi F, Ceccherini-Nelli L, Pistello M. Viral vectors: a look back and ahead on gene transfer technology. New Microbiol. 2013;36(1):1-22.

62. Chen $Y$, Xianyu $Y$, Jiang $X$. Surface modification of gold nanoparticles with small molecules for biochemical analysis. Acc Chem Res. 2017;50(2):310-9.

63. Jia C, Chen H, Wei M, Chen X, Zhang Y, Cao L, et al. Gold nanoparticlebased miR155 antagonist macrophage delivery restores the cardiac function in ovariectomized diabetic mouse model. Int J Nanomedicine. 2017; 12:4963-79

64. Mamaeva V, Sahlgren C, Linden M. Mesoporous silica nanoparticles in medicine-Recent advances. Adv Drug Deliver Rev. 2013;65(5):689-702.

65. Li Y, Duo Y, Bi J, Zeng X, Mei L, Bao S, et al. Targeted delivery of anti-miR155 by functionalized mesoporous silica nanoparticles for colorectal cancer therapy. Int J Nanomedicine. 2018;13:1241-56.

66. Loh KP, Bao QL, Eda G, Chhowalla M. Graphene oxide as a chemically tunable platform for optical applications. Nat Chem. 2010;2(12):1015-24.

67. Hwang DW, Kim HY, Li FY, Park JY, Kim D, Park JH, et al. In vivo visualization of endogenous miR-21 using hyaluronic acid-coated graphene oxide for targeted cancer therapy. Biomaterials. 2017;121:144-54.

68. Sun S, Wang Y, Zhou R, Deng Z, Han Y, Han X, et al. Targeting and regulating of an oncogene via Nanovector delivery of MicroRNA using patient-derived xenografts. Theranostics. 2017;7(3):677-93.

69. Pedroso de Lima MC, Simoes S, Pires P, Faneca H, Duzgunes N. Cationic lipid-DNA complexes in gene delivery: from biophysics to biological applications. Adv Drug Deliv Rev. 2001;47(2-3):277-94.

70. Silva BFB, Majzoub RN, Chan CL, Li YL, Olsson U, Safinya CR. PEGylated cationic liposome-DNA complexation in brine is pathway-dependent. BbaBiomembranes. 2014;1838(1):398-412.
71. Endo-Takahashi Y, Negishi Y, Nakamura A, Ukai S, Ooaku K, Oda Y, et al. Systemic delivery of miR-126 by miRNA-loaded bubble liposomes for the treatment of hindlimb ischemia. Sci Rep. 2014;4:3883.

72. Zhang Q, Ran R, Zhang L, Liu Y, Mei L, Zhang Z, et al. Simultaneous delivery of therapeutic antagomirs with paclitaxel for the management of metastatic tumors by a pH-responsive anti-microbial peptide-mediated liposomal delivery system. J Control Release. 2015;197:208-18.

73. Hobel S, Aigner A. Polyethylenimines for siRNA and miRNA delivery in vivo. Wiley Interdiscip Rev Nanomed Nanobiotechnol. 2013;5(5):484-501.

74. Jager M, Schubert S, Ochrimenko S, Fischer D, Schubert US. Branched and linear poly(ethylene imine)-based conjugates: synthetic modification, characterization, and application. Chem Soc Rev. 2012; 41(13):4755-67.

75. Lin CW, Jan MS, Kuo JS. The vector-related influences of autophagic microRNA delivery by Lipofectamine 2000 and polyethylenimine 25K on mouse embryonic fibroblast cells. Eur J Pharm Sci. 2017;101:11-21.

76. Huang Z, Shi T, Zhou Q, Shi S, Zhao R, Shi H, et al. miR-141 regulates colonic leukocytic trafficking by targeting CXCL12beta during murine colitis and human Crohn's disease. Gut. 2014;63(8):1247-57.

77. Shi T, Xie Y, Fu Y, Zhou Q, Ma Z, Ma J, et al. The signaling axis of microRNA31/interleukin-25 regulates Th1/Th17-mediated inflammation response in colitis. Mucosal Immunol. 2017;10(4):983-95.

78. Avci CB, Ozcan I, Balci T, Ozer O, Gunduz C. Design of polyethylene glycolpolyethylenimine nanocomplexes as non-viral carriers: mir-150 delivery to chronic myeloid leukemia cells. Cell Biol Int. 2013;37(11):1205-14.

79. Gao S, Tian H, Guo Y, Li Y, Guo Z, Zhu X, et al. miRNA oligonucleotide and sponge for miRNA-21 inhibition mediated by PEI-PLL in breast cancer therapy. Acta Biomater. 2015;25:184-93.

80. Danhier F, Ansorena E, Silva JM, Coco R, Le Breton A, Preat V. PLGA-based nanoparticles: an overview of biomedical applications. J Control Release. 2012;161(2):505-22.

81. Cai C, Xie Y, Wu L, Chen X, Liu H, Zhou Y, et al. PLGA-based dual targeted nanoparticles enhance miRNA transfection efficiency in hepatic carcinoma. Sci Rep. 2017;7:46250.

82. Martirosyan A, Olesen MJ, Howard KA. Chitosan-based nanoparticles for mucosal delivery of RNAi therapeutics. Adv Genet. 2014;88:325-52.

83. van Vliet SJ, Saeland E, van Kooyk Y. Sweet preferences of MGL: carbohydrate specificity and function. Trends Immunol. 2008;29(2):83-90.

84. Gao SY, Chen JN, Xu XR, Ding Z, Yang YH, Hua ZC, et al. Galactosylated low molecular weight chitosan as DNA carrier for hepatocyte-targeting. Int J Pharm. 2003;255(1-2):57-68.

85. Gao S, Chen J, Dong L, Ding Z, Yang YH, Zhang J. Targeting delivery of oligonucleotide and plasmid DNA to hepatocyte via galactosylated chitosan vector. Eur J Pharm Biopharm. 2005;60(3):327-34.

86. Dong L, Gao SY, Diao HJ, Chen JN, Zhang JF. Galactosylated low molecular weight chitosan as a carrier delivering oligonucleotides to Kupffer cells instead of hepatocytes in vivo. J Biomed Mater Res A. 2008;84a(3):777-84.

87. Zuo L, Huang Z, Dong L, Xu L, Zhu Y, Zeng K, et al. Targeting delivery of anti-TNFalpha oligonucleotide into activated colonic macrophages protects against experimental colitis. Gut. 2010;59(4):470-9.

88. Huang Z, Ma J, Chen M, Jiang H, Fu Y, Gan J, et al. Dual TNF-alpha/IL-12p40 interference as a strategy to protect against colitis based on miR-16 precursors with macrophage targeting vectors. Mol Ther. 2015;23(10):1611-21.

89. Tejashri G, Amrita B, Darshana J. Cyclodextrin based nanosponges for pharmaceutical use: a review. Acta Pharma. 2013;63(3):335-58.

90. Zeng Y, Zhou Z, Fan M, Gong T, Zhang Z, Sun X. PEGylated cationic vectors containing a protease-sensitive peptide as a miRNA delivery system for treating breast Cancer. Mol Pharm. 2017;14(1):81-92.

91. Gothwal A, Khan I, Gupta U. Polymeric micelles: recent advancements in the delivery of anticancer drugs. Pharm Res. 2016;33(1):18-39.

92. Salzano G, Costa DF, Sarisozen C, Luther E, Mattheolabakis G, Dhargalkar PP, et al. Mixed Nanosized polymeric micelles as promoter of doxorubicin and miRNA-34a co-delivery triggered by dual stimuli in tumor tissue. Small. 2016;12(35):4837-48

93. Wu LP, Ficker M, Christensen JB, Trohopoulos PN, Moghimi SM. Dendrimers in medicine: therapeutic concepts and pharmaceutical challenges. Bioconjug Chem. 2015;26(7):1198-211.

94. Abbasi E, Aval SF, Akbarzadeh A, Milani M, Nasrabadi HT, Joo SW, et al. Dendrimers: synthesis, applications, and properties. Nanoscale Res Lett. 2014;9(1):247. 
95. Wang F, Zhang B, Zhou L, Shi Y, Li Z, Xia Y, et al. Imaging dendrimergrafted graphene oxide mediated anti-miR-21 delivery with an Activatable luciferase reporter. ACS Appl Mater Interfaces. 2016;8(14):9014-21.

96. Robbins PD, Morelli AE. Regulation of immune responses by extracellular vesicles. Nat Rev Immunol. 2014;14(3):195-208.

97. EL Andaloussi S, Maeger I, Breakefield XO, Wood MJA. Extracellular vesicles: biology and emerging therapeutic opportunities. Nat Rev Drug Discov. 2013;12(5):348-58.

98. Wang YY, Chen X, Tian BQ, Liu JF, Yang L, Zeng LL, et al. Nucleolin-targeted extracellular vesicles as a versatile platform for biologics delivery to breast Cancer. Theranostics. 2017;7(5):1360-72.

99. Tominaga N, Kosaka N, Ono M, Katsuda T, Yoshioka Y, Tamura K, et al. Brain metastatic cancer cells release microRNA-181c-containing extracellular vesicles capable of destructing blood-brain barrier. Nat Commun. 2015;6:6716.

100. Simons M, Raposo G. Exosomes - vesicular carriers for intercellular communication. Curr Opin Cell Biol. 2009;21(4):575-81.

101. Ha D, Yang NN, Nadithe V. Exosomes as therapeutic drug carriers and delivery vehicles across biological membranes: current perspectives and future challenges. Acta Pharm Sin B. 2016;6(4):287-96.

102. Lee JH, Kim JA, Kwon MH, Kang JY, Rhee WJ. In situ single step detection of exosome microRNA using molecular beacon. Biomaterials. 2015;54:116-25.

103. Zhou Y, Li P, Goodwin AJ, Cook JA, Halushka PV, Chang E, et al. Exosomes from endothelial progenitor cells improve the outcome of a murine model of Sepsis. Mol Ther. 2018;26(5):1375-84.

104. Wen D, Peng Y, Liu D, Weizmann Y, Mahato RI. Mesenchymal stem cell and derived exosome as small RNA carrier and Immunomodulator to improve islet transplantation. J Control Release. 2016;238:166-75.

105. Munagala R, Aqil F, Jeyabalan J, Gupta RC. Bovine milk-derived exosomes for drug delivery. Cancer Lett. 2016;371(1):48-61.

106. Raposo G, Stoorvogel W. Extracellular vesicles: exosomes, microvesicles, and friends. J Cell Biol. 2013;200(4):373-83.

107. Yang J, Zhou CZ, Zhu R, Fan H, Liu XX, Duan XY, et al. miR-200b-containing microvesicles attenuate experimental colitis associated intestinal fibrosis by inhibiting epithelial-mesenchymal transition. J Gastroenterol Hepatol. 2017:32(12):1966-74

108. Zhang H, Bai M, Deng T, Liu R, Wang X, Qu Y, et al. Cell-derived microvesicles mediate the delivery of miR-29a/c to suppress angiogenesis in gastric carcinoma. Cancer Lett. 2016;375(2):331-9.

109. Cui J, Li Q, Luo M, Zhong Z, Zhou S, Jiang L, et al. Leukemia cell-derived microvesicles induce T cell exhaustion via miRNA delivery. Oncoimmunology. 2018;7(7):e1448330.

110. Leslie M. Cell biology. Beyond clotting: the powers of platelets. Science. 2010;328(5978):562-4.

111. Laffont B, Corduan A, Ple H, Duchez AC, Cloutier N, Boilard E, et al. Activated platelets can deliver mRNA regulatory Ago2.microRNA complexes to endothelial cells via microparticles. Blood. 2013;122(2):253-61.

112. Liang $H$, Yan $X$, Pan $Y$, Wang Y, Wang N, Li L, et al. MicroRNA-223 delivered by platelet-derived microvesicles promotes lung cancer cell invasion via targeting tumor suppressor EPB41L3. Mol Cancer. 2015;14:58.

113. Akers JC, Gonda D, Kim R, Carter BS, Chen CC. Biogenesis of extracellular vesicles (EV): exosomes, microvesicles, retrovirus-like vesicles, and apoptotic bodies. J Neuro-Oncol. 2013:113(1):1-11.

114. Segawa K, Nagata S. An apoptotic 'Eat Me' signal: phosphatidylserine exposure. Trends Cell Biol. 2015:25(11):639-50.

115. Zernecke A, Bidzhekov K, Noels H, Shagdarsuren E, Gan L, Denecke B, et al. Delivery of microRNA-126 by apoptotic bodies induces CXCL12-dependent vascular protection. Sci Signal. 2009;2(100):ra81.

116. Nguyen MK, Jeon $O$, Dang PN, Huynh $C T$, Varghai $D$, Riazi $H$, et al. RNA interfering molecule delivery from in situ forming biodegradable hydrogels for enhancement of bone formation in rat calvarial bone defects. Acta Biomater. 2018:75:105-114.

117. Conde J, Oliva N, Atilano M, Song HS, Artzi N. Self-assembled RNA-triplehelix hydrogel scaffold for microRNA modulation in the tumour microenvironment. Nat Mater. 2016;15(3):353-63.

118. Zhou F, Jia X, Yang Y, Yang Q, Gao C, Hu S, et al. Nanofiber-mediated microRNA-126 delivery to vascular endothelial cells for blood vessel regeneration. Acta Biomater. 2016:43:303-13.

119. Zhang X, Li Y, Chen YE, Chen J, Ma PX. Cell-free 3D scaffold with two-stage delivery of miRNA-26a to regenerate critical-sized bone defects. Nat Commun. 2016;7:10376.
120. Mencia Castano I, Curtin CM, Shaw G, Murphy JM, Duffy GP, O'Brien FJ. A novel collagen-nanohydroxyapatite microRNA-activated scaffold for tissue engineering applications capable of efficient delivery of both miR-mimics and antagomiRs to human mesenchymal stem cells. J Control Release. 2015;200:42-51.

121. Gebert LFR, Rebhan MAE, Crivelli SEM, Denzler R, Stoffel M, Hall J. Miravirsen (SPC3649) can inhibit the biogenesis of miR-122. Nucleic Acids Res. 2014;42(1):609-21.
Ready to submit your research? Choose BMC and benefit from:

- fast, convenient online submission

- thorough peer review by experienced researchers in your field

- rapid publication on acceptance

- support for research data, including large and complex data types

- gold Open Access which fosters wider collaboration and increased citations

- maximum visibility for your research: over $100 \mathrm{M}$ website views per year

At $\mathrm{BMC}$, research is always in progress.

Learn more biomedcentral.com/submissions 